\title{
Si hay otros mundos, se linkan en éste
}

César Fernández Fernández Universitat Jaume I

Investigar en comunicación, desde las ciencias sociales y humanas, conlleva, sin duda, necesariamente, comunicar investigación. Investigar en otros campos o dominios puede conllevar una aplicación directa, sin más, manteniéndose con ello dentro de los dominios de la utilidad o de la ética. Al hacerlo en comunicación salimos de tales dominios si no la comunicamos a su vez. Y, al decir comunicar investigación — sea comunicar hacer llegar, interesar, activar, y sea investigación tiempo dedicado, sistémico y creativo- ¿qué importancia tiene la ordenación de tales procesos frente a su esencia? En vez de dar una respuesta a esta pregunta - en este texto introductorio de la sección Otras investigaciones- mejor cuestionar, de nuevo, sobre si cierta obsesión por ordenar no será debida a «nuestro hábito inveterado de pensar la diferencia a partir de las categorías de la representación» (Delleuze, 2002: 186). Si ya el concepto de intertextualidad pone en conflicto - en el dominio epistemológico- la noción de alteridad, el hipertexto electrodigital arrincona definitivamente la otredad al dominio ontológico, aquél donde Sarte, Lévinas, Foucault, Lacan, Derrida, entre otros, nos la definen. La interNodalidad, multiModalidad y no linealidad del hipertexto y el hipermedia, cuanto menos obligan al replanteamiento de las estrategias y esencias del orden, en la escritura, la lectura, la edición. Bien se puede decir que en la comunicación digital «hay unión sin unificación, aproximación sin proximidad y alejamiento sin distancia» (Arabi, 2002: 53). Paradójicamente, es la tecnología asentada en la diferencia pura - precisando y limitando la posibilidad de lo otro a dos elementos, el 0 y el 1 - la que nos abre la potencia comunicativa de la infinita promiscuidad conceptual, formal y estructural bajo control. Es verdad que el Álgebra de Boole al servicio de la comunicación se manifiesta a nuestros sentidos en espacios de «anverso infinito» (Fernández, 2004) 
y que en el papel los links sólo van y vienen sinápticamente, pero (casi) todo lo ordenadamente impreso empieza ya a encontrar su des-orden correspondiente en el ciberespacio. Así, la expansión que le supone al texto perder su reverso y ganar, junto a los sinápticos, los quiroenlaces digitales, insertándose en el hipermedia con estrategias multiconfigurables de localización cronotopológica, obliga a cuestionarnos - en el dominio de la edición, pero también de la producción de textos (de investigación) en sí- los conceptos de actualidad e impacto, para sustituirlos por el de pertinencia, y a cambiar la práctica exacerbada de la citación por la de la creación de relevancia y original. Para nada quiere eso decir que abdiquemos de las relaciones intelectuales, ideológicas o autorales, al contrario, multiplíquense en direcciones inter/multi-disciplinares, pero siempre buscando el valor añadido, no la simple hibridación. Igualmente, mantengamos el valor de la especialización, entendida como una focalización, como un direccionamiento, y no como una poda. Sea pues la investigación, más que nunca en la era digital, una convocatoria de saberes y de saber. Lo cual esperamos que puedan encontrar los lectores en los artículos que a continuación se relatan y que componen esta sección de Otras investigaciones del número 5 de la revista científica de estrategias, tendencias e innovación en comunicación adComunica.

La esencia de un concepto tan bello como el que designa el término Democracia rara vez se ha visto concretada en la Historia y/o la Geografía de nuestro planeta. ¿Acaso en la era digital y la globalización podría? Ramón Zallo Elguezabal, en su artículo «Comunicación y democracia en el entorno digital», nos demuestra que, desde luego, no está siendo así y, si puede serlo en el futuro, no será algo automático que derive simplemente de la tecnologización y des- (o re-) fronterización del mundo. Su investigación nos propone pensar — desde una idea de neomodernidad, basada en la ética y rescatadora de la Historia y la memoria ideológica - en mecanismos que compatibilicen la democracia representativa, la presencial y la cibernética. El autor nos evidencia cómo, los lazos de la comunicación y la cultura con la democracia, no conllevan necesariamente en nuestros tiempos que esta última mejore porque las primeras se tele-digito-reticularicen: en medio de diversas brechas digitales de nuestra sociedad (que se añaden a otras diversas brechas analógicas anteriores) afloran macropoderes en forma de micropoderes entramados en red que toman el control simultáneo de las redes y servicios del sistema de telecomunicaciones y las áreas de contenidos y plataformas. Estos señores de las redes - amparados en la desregularización global y en contratos que, de forma adhesiva, aceptan los usuarios- desplazan la política por las finanzas, lo que conlleva una crisis democrática y una deriva autoritaria, incluso represiva. En este artículo se pone de relieve cómo la crisis de legitimidad democrática en la era de la información digital, se caracteriza por internautas y ciudadanos que se enfrascan en información de segundo nivel, sobre la que operan mediante juicios rápidos, sumarios, poco contrastados y guiados por liderazgos prescriptores derivados de los poderes analógicos, aunque también por los emergentes en las redes. El lector de este artículo también encontrará en sus páginas interesantes propuestas, sólidamente argumentadas, 
de cómo la sociedad civil puede hacer valer las excelencias de la comunicación digital para contribuir a la emergencia de narrativas alternativas y acciones online y offline, encaminadas a la construcción de bloques hegemónicos que permitan una democracia esencial, al servicio de los sujetos y no de las corporaciones. Un artículo cuya metodología científica se basa en la lúcida conjugación de la deducción de ideas con el aporte y análisis de datos de gran relevancia y pertinencia para tales deducciones.

José Ignacio Aguaded Gómez y Jacqueline Sánchez Carrero, nos presentan —en su artículo «El empoderamiento digital de niños y jóvenes a través de la producción audiovisual»- una propuesta conceptual original de la idea de educación/ alfabetización mediática y, a la vez, un estudio aplicado al respecto. Centrándose en una población de estudio definida por la franja de edades que Piaget denominó como «segunda infancia» (acortada aquí de los 7 a los 11 años, para corregir la edad de los 12, ya en nuestra época inmersa en la pre-adolescencia), en este artículo se desarrolla una experiencia de aplicación de los actuales criterios planteados por instituciones europeas e internacionales en torno a la idea de alfabetización mediática, que aúnan las nociones de análisis y síntesis, de crítica y producción, para llegar a la consideración del sujeto activo como aquel capaz de comprender, valorar, crear y proponer, en el ámbito audiovisual. Así, diversos géneros comunicativos y mediáticos son utilizados como material de estudio respecto de su comprensión y capacitación operativa por parte de la población muestral escogida, a través de la articulación estratégica entre una definición particular de talleres y de variables. Se valoran, igualmente, en el ámbito del estudio, aspectos relativos a la educación formal e informal, escolar y extra-escolar, multidisciplinar y específica, recordándonos cómo la alfabetización mediática debe considerar los nuevos medios pero también los anteriores, sean cuales sean las plataformas de recepción (lectura en sentido amplio), asimilación (crítica en sentido amplio) o producción (escritura en sentido amplio).

El artículo «Percepción de la publicidad en tabletas digitales. Estudio experimental comparado de las ediciones en iPad y en papel de un diario», de Antonio Sanjuán Pérez, Natalia Quintas Froufe y Sandra Martínez Costa, se centra principalmente - a través de una estrategia basada en encuestas y focus groups sobre una muestra de estudiantes universitarios de 18 a 24 años- en analizar de un modo comparativo el nivel de recuerdo, visibilidad y rechazo de la publicidad en prensa en relación al soporte en el que se inserta y en determinar si los formatos de publicidad en prensa deben adaptarse al iPad en cuanto a tamaño e interactividad. En el artículo, entre otros, se presentan resultados del estudio tales como que el único aspecto que ha influido en el recuerdo de los anuncios es el formato y no el soporte, que la intromisión publicitaria no es un factor considerado negativamente, que la publicidad en soportes electrónicos debería ser más interactiva. A su vez, otro de los resultados que se presentan es que, en los anuncios, el eslogan fue mencionado como elemento motivador predominante en el papel, mientras que en el iPad pasó desapercibido. Una conclusión, 
esta última, que, extrapolando, nos invita sin duda a pensar, o investigar — tal vez con preocupación- hasta qué punto pierde valor la componente verbal de la comunicación en determinados modos/soportes comunicativos que empiezan a generalizarse.

En el artículo «El friulano ${ }^{1}$ como resistencia de la identidad: Pasolini y Casarsa Della Delizia ${ }^{2} »$, su autora, Bernadette Rey Mimoso-Ruiz, nos ofrece unas claves esenciales para conocer y comprender mejor a uno de los grandes actores y autores universales de la comunicación artística, política y social: Pier Paolo Pasolini. Sus obras, ensayos y estudios teóricos en crítica y producción literarias, cinematográficas, periodísticas —en suma, en comunicación y esencia humanas - son ejemplo de la conjunción entre actitud, práctica e ideología. Y en este artículo podemos descubrir de qué forma se forjaron en Pasolini los orígenes de dicha conjunción a través de la resistencia en un idioma. Un artículo apoyado en oportunas e interesantes referencias históricas y genealógicas, que invita a pensar las esencias de la comunicación, así como la situación de determinados conflictos actuales en torno a la identidad individual y colectiva.

El texto «Responsabilidad Social y Empresa Sostenible», de Anna Bajo Sanjuán, Marta González Álvarez y José Luis Fernández Fernández, es un artículo que revisa los conceptos que su título expresa, en relación a una concepción integrada - o integradora- del sistema económico y la sociedad en su conjunto. Se nos presenta cómo, en un mundo globalizado con creciente protagonismo de los mercados de capitales, las empresas están llamadas a considerar la responsabilidad social y la sostenibilidad como una forma de entender su actividad más allá de estrategias de marketing, cortoplacistas o de corrección política, considerando la teoría del stakeholder de manera expandida, en cuanto a lo concernido (especialmente la sociedad, las personas, y el entorno natural) y en cuanto al abarque temporal (sobre todo mirando a las generaciones futuras). Así, se trata de hacer de un valor intangible algo concreto - mediante mecanismos de medición, verificación, comunicación, sensibilización, rentabilización e institucionalización - para que las empresas gestionen su desarrollo sostenible a través de la conocida triple dimensión económica, social y medioambiental.

\section{Referencias}

Arabi, Ibn (2002). Tratado de la unidad. Barcelona: Indigo.

Deleuze, Gilles (2002). Diferencia y repetición. Buenos Aires: Amorrortu.

Fernández Fernández, César (2004). El anverso infinito. Arte y comunicación en la era digital: del texto al hipermedia. Tesis Doctoral no publicada, dirigida por el Dr. Javier Marzal Felici. Castellón: Universitat Jaime I.

1 Idioma (dialecto) hablado en la provincia italiana del Friul, situada al pie de los Alpes.

2 Pueblo de la madre de Pasolini (situado en la provincia del Friul). 


\section{Referencia de este artículo}

Fernández Fernández, César (2013). Si hay otros mundos, se linkan en éste. En: adComunica. Revista Científica de Estrategias, Tendencias e Innovación en Comunicación, $\mathrm{n}^{0} 5$. Castellón: Asociación para el Desarrollo de la Comunicación adComunica, Universidad Complutense de Madrid y Universitat Jaume I, 135-139. DOI: http://dx.doi.org/10.6035/2174-0992.2013.5.9. 